\title{
PATIENT ASSOCIATIONS AS KEY PLAYERS IN PHARMACOVIGILANCE: RESULTS OF AN ITALIAN SURVEY FROM THE PATIENT SAFETY COUNCIL
}

\author{
P. Bandiera' ${ }^{1}$, M. Gianetta ${ }^{2}$, S. Leone ${ }^{3}$, A. Lupi ${ }^{4}$, D. Petruzzelli5, S. Bianco ${ }^{6}$ \\ ${ }^{1}$ Associazione Italiana Sclerosi Multipla AISM Onlus, Genoa, Italy \\ 2 WALCE Onlus - Women Against Lung Cancer in Europe c/o AOU San Luigi, SSD Oncologia Polmonare, \\ Regione Gonzole, Turin, Italy \\ ${ }^{3} \mathrm{AMICI}$ Onlus, Milan, Italy \\ ${ }^{4}$ FedEmo, Rome, Italy \\ ${ }^{5}$ La Lampada di Aladino Onlus, Brugherio, Monza-Brianza, Italy \\ ${ }^{6}$ AKROS BioScience S.r.l., Pomezia, Rome, Italy \\ E-mail: s.bianco@akrosbioscience.eu
}

Doi: $10.36118 /$ pharmadvances.2021.12

\begin{abstract}
SUMMARY
Despite an increasing role in selecting and evaluating treatments, Patient Associations (PAs) do not yet play a significant role in pharmacovigilance (PV). The Patient Safety Council (PSC) is an initiative that brings together five PAs (AISM, AMICI Onlus, Fedemo, La Lampada di Aladino, Walce). The aim of PSC is to encourage PAs to play an active role in patient education, reporting Adverse Drug Reactions (ADRs) and assessing the safety of treatments.

To this aim PSC carried out a survey to assess the level of information on PV among the members of the five associations and their interest in getting more information on PV.

A questionnaire was administered to patients recruited by the five PAs. The questions were grouped into three clusters exploring: 1) Level of knowledge of patients about PV. 2) Sources of information and their behavior regarding reporting ADRs. 3) Interest in receiving more information on PV.

The survey received 1,368 replies. In the first cluster more than $80 \%$ of the participants stated that they had little or no knowledge of PV. In the second cluster 35\% of the patients never reported any ADR they had experienced. Among those who reported ADRs, they mainly contacted their specialist (46\%) or general practitioner (35\%). Most of the patients were not aware they could report ADRs directly to the Competent Authority. Finally, more than $80 \%$ of the patients stated they would like to receive more information on PV.

There is an unmet need in the field of information and education of patients regarding PV. There is also a great deal of interest among the patients to be informed on PV. PAs could play a significant role in patient education and reporting of ADRs to the Competent Authorities.
\end{abstract}

\section{Key words}

Patient Associations; pharmacovigilance; patient safety council; survey; patients empowerment.

\section{Impact statement}

Patient Associations (PAs) are not involved in pharmacovigilance; a survey by the Patient Safety Council shows that PAs could give a crucial contribution to the safety evaluation of treatment. 


\section{INTRODUCTION}

In the last years, the active role of patients in medicine is gaining ground under the name of patient empowerment (1). The World Health Organization (WHO) defines empowerment as "a process through which people gain greater control over decisions and actions affecting their health". Patient empowerment is both an individual and a community process (2). Patient Associations (PAs) play a pivotal role in patient empowerment, supporting patients and their families and sharing experiences and good practices. In addition, PAs stimulate scientific research, actions, and socio-sanitary interventions by providing a different type of knowledge from the medical or institutional sources (3).

Advances in information technologies allowed the PAs to reach a larger number of patients and enhance their interaction, setting up virtual health communities with an increasing influence on the decision-makers $(4,5)$. This evolution positively impacted several health outcomes, such as treatment adherence and self-care practices and favored the development of innovative medicines that better satisfy the unmet needs and priorities of patients (6). At present, patients are being involved in different stages of medicine developmental processes, including definition of unmet needs $(7,8)$; design of the clinical program and clinical trials (9); early dialogue with Regulators, Health Technology Assessment bodies and Competent Authorities during the approval and post-approval phases (10-15). On the other hand, patients' involvement in research ethics committees has not yet been clearly de- fined (16). From their side, Regulatory Authorities are increasingly planning to involve patients and PAs in their activities (17). Despite its fast evolution in the last years (18), pharmacovigilance (PV) has not been fully included in this evolving scenario in Italy. Indeed, we are currently in the era of Pharmacovigilance 2.0, a revolutionary change made possible by digitalization. In healthcare, with the fast diffusion of electronic diagnostic and monitoring tools, health information on medical conditions, medicines and Adverse Drug Reactions (ADRs) has been shared in a quantity and at a speed unthinkable in the past (19). An increasing number of drugs are being approved after short trials involving few patients; therefore, accurate reports of AEs and side effects following approval are becoming imperative. Real-world evidence obtained by patients is gaining paramount importance in regulatory evaluations (18). Independent and subjective patient reporting is crucial, as physicians often underestimate or dismiss specific side effects like fatigue and overestimate others.

Moreover, poor knowledge of the safety profile of a drug can lead to incorrect risk perception in patients and inappropriate behavior. Developing a culture of adequate reporting of ADRs in physicians and patients will improve the knowledge of a drug's safety profile and improve patients' care standards. Considering the above evidence, the Company Roche SpA facilitated the creation of a Patient Safety Council (PSC) by involving five PAs representing, at a national level, people affected by major pathologies (table I). The aim of the PSC is

Table I. Patients Associations participating in Patient Safety Council.

\begin{tabular}{|l|l|}
\hline ASSOCIATION & PATHOLOGY \\
\hline $\begin{array}{l}\text { AMICI: Associazione Malattie Infiammatorie Croniche } \\
\text { Intestinali }\end{array}$ & Chronic Inflammatory Bowel Diseases \\
\hline AISM: Associazione Italiana Sclerosi Multipla & Multiple Sclerosis \\
\hline Fedemo: Federazione Associazione Emofilici & Haemophilia \\
\hline Lampada di Aladino & Cancer \\
\hline WALCE: Women Against Lung Cancer & Lung Cancer \\
\hline
\end{tabular}


to enhance the awareness and knowledge of patients and PAs on PV issues by co-creating an educational and information pathway on PV. The first activity of the PSC was to prepare an Italian survey, which was administered to patients recruited by the five participating PAs. The survey collected data on the level of knowledge of the participants on PV, their behavior in case of the onset of ADRs, and their interest in receiving further information about PV. These data will help identify the needs of patients and PAs on PV and lay the basis for a discussion with the different stakeholders. Shared projects will be developed from this collaboration, like a common training course on PV for patients and PAs and useful indications for decision-makers.

\section{METHODS}

Data were collected from five different PAs of the PSC: AISM, AMICI Onlus, Fedemo, La Lampada di Aladino, Walce, with an overall of 1,368 answers received. The above-mentioned PAs represent patients affected by diseases with a significant burden on the Quality of Life and Healthcare Systems: chronic inflammatory bowel diseases, congenital coagulation disorders, multiple sclerosis, cancer (table I). The questions of the survey were discussed and agreed by the five PAs. The questions were grouped into three clusters that investigated three different areas:

- cluster 1: level of knowledge of the participants on the PV topic (two questions);

- cluster 2: behavior of patients in case of the onset of ADRs (six questions);

- cluster 3: interest of patients in receiving further information about PV (two questions).

The PAs administered the survey to patients recruited through different media (website, Facebook, mailing, etc.). Because of the preliminary nature of the survey and in order to minimize any privacy issue, the questionnaire did not collect data on demographic parameters like age and gender or data concerning employment or level of education. For this reason, stratification of the involved population was not possible. The survey was distributed from November to December 2020. Participants had two months to answer and data were collected in the first quarter of 2021. As a descriptive study, no statistical analysis was performed.

\section{RESULTS}

The number of patients answering the questions of the survey is presented in table II.

\section{Cluster 1: the level of knowledge of the participants on the PV topic}

1,368 responses were received from 1,368 patients: 1,082 were affected by chronic inflammatory bowel diseases, 138 by multiple sclerosis, 129 by cancer and 19 by congenital coagulation disorders. Half of the 1,368 patients declared to be poorly informed on PV. As for the remaining participants, 23\% answered they were not informed about PV, with only $3 \%$ claiming some knowledge on the topic. Patients were asked if they had ever received information about PV. Of the participants, 60\% reported they had never received information about PV. The rest of the participants were equally divided among those being informed by the specialist or the general practitioner, and those collecting information from social media and web (figure 1).

\section{Cluster 2: the behavior of the participants in case of the onset of AEs}

The second cluster of questions explored the behavior of patients in case of occurrence of an AE. A large share of patients (74\%) experienced an ADR in their life. Patients who had AEs reported the symptoms mainly to the specialist $(46 \%)$ or general practitioner (18\%) under whose care they were treated. About one third $(35 \%)$ of the participants never reported the ADRs experienced. Almost all (89\%) of the participants had never been informed about the possibility of directly reporting ADRs to 
Table II. Number of patients answering the questions of clusters 1, 2 and 3 of the survey.

\begin{tabular}{|c|c|c|c|c|c|c|c|}
\hline \multirow{2}{*}{$\begin{array}{l}\text { Questions } \\
\text { 1. Level of knowledge of the } \\
\text { participants on the PV topic }\end{array}$} & \multicolumn{7}{|c|}{ Number of patients answering } \\
\hline & & & & & & & \\
\hline \multirow{2}{*}{$\begin{array}{l}\text { How informed do you feel } \\
\text { about PV? }\end{array}$} & A lot & Somewhat & A little & Not at all & & & \\
\hline & 43 & 326 & 686 & 313 & & & \\
\hline \multirow[t]{2}{*}{$\begin{array}{l}\text { Have you ever received } \\
\text { information on PV? From } \\
\text { whom? }\end{array}$} & $\begin{array}{l}\text { Yes, } \\
\text { from the } \\
\text { specialist }\end{array}$ & No & $\begin{array}{l}\text { Yes, from } \\
\text { social and } \\
\text { web }\end{array}$ & $\begin{array}{l}\text { Yes, from } \\
\text { the general } \\
\text { practitioner }\end{array}$ & & & \\
\hline & 205 & 798 & 176 & 155 & & & \\
\hline \multicolumn{8}{|l|}{$\begin{array}{l}\text { 2. Patients' behavior in case } \\
\text { of the onset of ADRs }\end{array}$} \\
\hline \multirow[t]{2}{*}{$\begin{array}{l}\text { Have you ever had any } \\
\text { symptoms associated with an } \\
\text { ADR? }\end{array}$} & $\begin{array}{l}\text { Yes, more } \\
\text { than once } \\
\text { in the last } \\
\text { year }\end{array}$ & $\begin{array}{l}\text { Yes, once } \\
\text { in the last } \\
\text { year }\end{array}$ & $\begin{array}{l}\text { Yes, but } \\
\text { not in the } \\
\text { last year }\end{array}$ & No, never & & & \\
\hline & 277 & 197 & 552 & 352 & & & \\
\hline \multirow[t]{2}{*}{$\begin{array}{l}\text { Did you report these symptoms } \\
\text { as ADRs? }\end{array}$} & $\begin{array}{c}\text { General } \\
\text { practitioner }\end{array}$ & Specialist & PAs & Pharmacist & $\begin{array}{c}\text { AlFA } \\
\text { website }\end{array}$ & $\begin{array}{l}\text { No } \\
\text { reporting }\end{array}$ & \\
\hline & 238 & 629 & 3 & 6 & 8 & 478 & \\
\hline \multirow{2}{*}{$\begin{array}{l}\text { Did you receive information } \\
\text { on the possibility of direct } \\
\text { reporting to AIFAs? }\end{array}$} & $\begin{array}{l}\text { General } \\
\text { practitioner }\end{array}$ & Specialist & PAs & $\begin{array}{l}\text { Informative } \\
\text { material }\end{array}$ & Web & $\begin{array}{c}\text { Other } \\
\text { channels }\end{array}$ & $\begin{array}{l}\text { No, } \\
\text { never }\end{array}$ \\
\hline & 0 & 29 & 4 & 71 & 41 & 4 & 1181 \\
\hline \multirow[t]{2}{*}{$\begin{array}{l}\text { Have you ever directly reported } \\
\text { ADRs to AIFA? }\end{array}$} & $\begin{array}{l}\text { Yes, I took } \\
\text { care of it }\end{array}$ & $\begin{array}{l}\text { Yes, my } \\
\text { caregiver } \\
\text { did }\end{array}$ & No, never & & & & \\
\hline & 41 & 3 & 1324 & & & & \\
\hline \multirow[t]{2}{*}{$\begin{array}{l}\text { What channels do you use to } \\
\text { get information on the ADRs? }\end{array}$} & $\begin{array}{c}\text { General } \\
\text { practitioner }\end{array}$ & Specialist & Pharmacist & $\begin{array}{l}\text { Package } \\
\text { leaflet }\end{array}$ & Internet & PAs & Other \\
\hline & 142 & 265 & 24 & 678 & 111 & 6 & 15 \\
\hline \multirow[t]{2}{*}{$\begin{array}{l}\text { Is the information on ADRs in } \\
\text { the package leaflet clear? }\end{array}$} & Very clear & $\begin{array}{c}\text { Clear } \\
\text { enough }\end{array}$ & Unclear & $\begin{array}{l}\text { Not at all } \\
\text { clear }\end{array}$ & $\begin{array}{l}\text { I don't } \\
\text { read the } \\
\text { package } \\
\text { leaflet }\end{array}$ & & \\
\hline & 135 & 913 & 228 & 39 & 49 & & \\
\hline \multicolumn{8}{|l|}{$\begin{array}{l}\text { 3. Patients' interest } \\
\text { in receiving further } \\
\text { information about PV }\end{array}$} \\
\hline \multirow[t]{2}{*}{$\begin{array}{l}\text { Would you like to receive } \\
\text { information on PV from the PA? }\end{array}$} & Yes & No & $\begin{array}{l}\text { I already } \\
\text { receive } \\
\text { them }\end{array}$ & & & & \\
\hline & 1118 & 180 & 69 & & & & \\
\hline \multirow[t]{2}{*}{ Which mode would you prefer? } & $\begin{array}{l}\text { Internet } \\
\text { website }\end{array}$ & $\begin{array}{l}\text { Dedicated } \\
\text { app }\end{array}$ & $\begin{array}{l}\text { Paper } \\
\text { brochure }\end{array}$ & $\begin{array}{l}\text { Online } \\
\text { tutorial }\end{array}$ & Other & & \\
\hline & 659 & 233 & 267 & 162 & 60 & & \\
\hline
\end{tabular}

PV: pharmacovigilance; ADRs: adverse drug reactions; PAs: Patient Associations; AIFA: Agenzia Italiana del Farmaco, Italian Medicines Agency. 


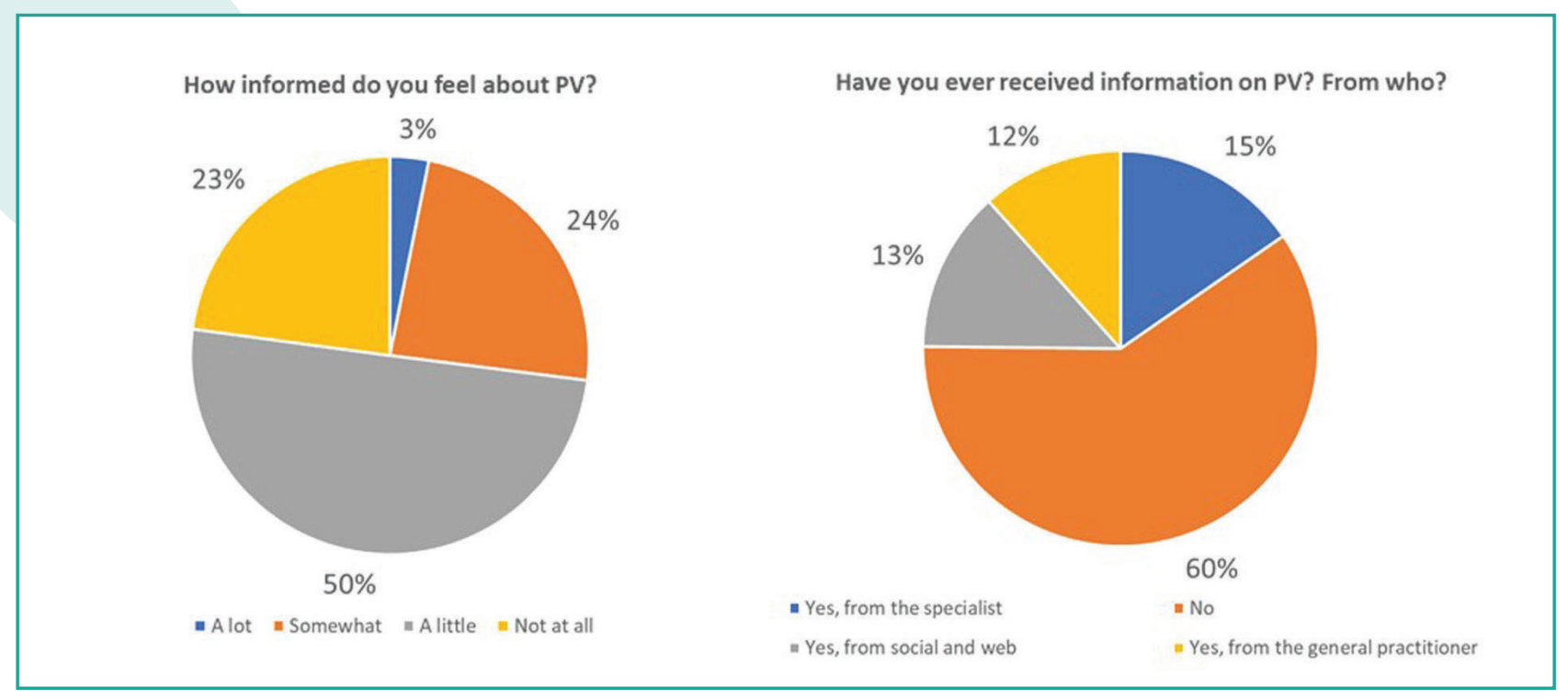

Figure 1. Level of knowledge of the participants on the PV topic (cluster 1 of the survey).

the Italian Medicines Agency (Agenzia Italiana del Farmaco, AIFA), with $6 \%$ receiving such information from informative material, $3 \%$ from the Internet and $2 \%$ from the specialist. Among the 1,368 patients involved, 97\% never directly reported an ADR to AIFA. The most used source of information on the ADRs was the package leaflet (55\%), direct questioning to the reference specialists as a second option (21\%). Internet and the general practitioner resulted less used. The survey interrogated the patients about the clarity of ADRs in the package leaflet. More than half $(67 \%)$ of the patients considered this information clear enough to be understood, with $17 \%$ of opposite opinion (figure 2).

\section{Cluster 3: the interest of the participants in receiving further information about PV}

The last cluster of questions aimed to assess the interest of the participants in PV. The vast majority (82\%) of participants stated they would like to receive information on PV from the PA, with $13 \%$ being of the opposite opinion. The preferred modality to receive information on PV consisted of Internet websites (48\%), followed by brochures (19\%), dedicated apps (17\%), and online tutorials (12\%) (figure 3 ).

\section{DISCUSSION}

This is the first Italian survey investigating the awareness and involvement of patients contacted by PAs in PV.

Among the strengths of this survey there is the participation of five national PAs, which allowed to explore the point of view of patients suffering from different diseases. Furthermore, since the questionnaire was disseminated through various systems (social media, email) it was possible to reach a wide range of patients. However, this work has some weaknesses. First of all, the methodology used did not allow a balancing of the pathologies. Moreover, privacy issues did not allow stratification of the population involved. Lastly, being a pilot survey, only descriptive data are available. Despite the weaknesses mentioned above, the results can be considered representative of the actual Italian situation.

The results of the survey give rise to some interesting considerations:

1) the survey confirmed the lack of adequate information from the scientific and institutional sources, even for patients affected by severe and chronic diseases who take complex treatment regimens and should be informed in detail about the possible ADRs. 


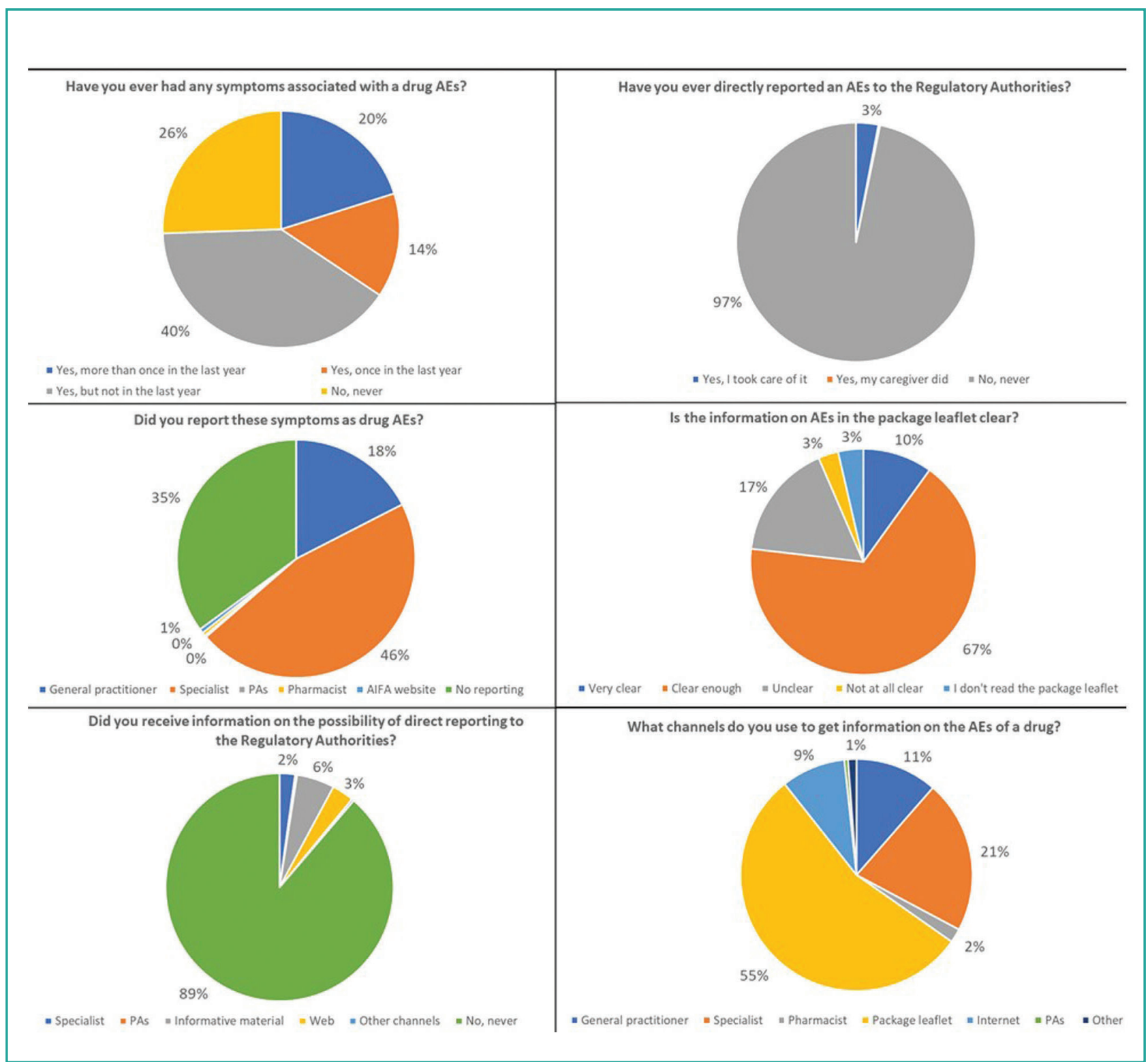

Figure 2. Behavior of the participants in case of the onset of AEs (cluster 2 of the survey).

2) More than $30 \%$ of the participants did not report the ADRs they experienced. The underreporting of ADRs represents a loss of valuable information for the safety and well-being of patients. The survey did not explore the reasons for the lack of reporting, which is a point worthy of further investigation. However, it is reasonable to think that the active involvement of PAs, which have an ongoing relationship with their members, could significantly reduce the above-mentioned loss of information.
3) The primary source of information for patients is the package leaflet. PAs could provide their patients useful insights on how to understand leaflets, basic PV concepts and address them to their physicians to discuss the risk benefit ratio of their treatments.

Finally, the survey brought to light the willingness of PAs to be more involved in PV. Indeed, all of the five PAs agreed to receive more information about PV and its processes, choosing the Internet as their favorite channel of information. 
Would you like to receive information on PV from the PA?

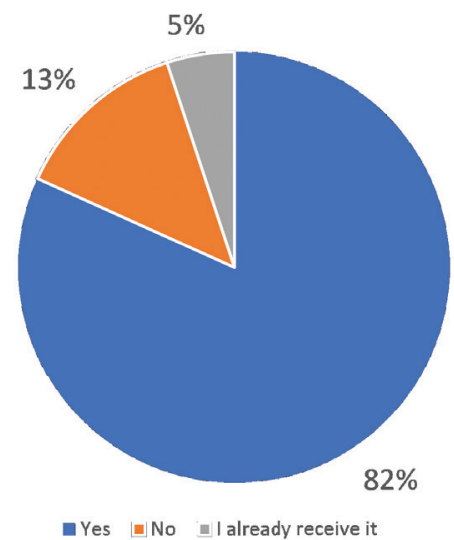

Which mode would you prefer? $4 \%$

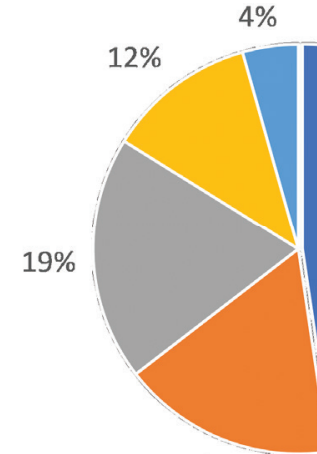

$17 \%$

- Internet website $\square$ Dedicated app $\quad$ Paper brochure $\square$ Online tutorial $\quad$ Other

Figure 3. Interest of participants in receiving further information about PV (cluster 3 of the survey).

Active collaboration among PAs, Regulatory Authorities, healthcare professionals and pharmaceutical companies could increase the culture around PV. This collaboration could lead to a greater ability of patients to detect and report ADRs adequately. A strengthened relationship between general practitioners and patients could lead to a fundamental improvement of the adherence to therapy and an increased capability of general practitioners to identify patients with higher risks of ADRs. Indeed, patient awareness about the risks and benefits of a treatment will result in a greater propensity to complete the whole treatment, avoiding abrupt or unnecessary interruptions.

\section{CONCLUSIONS}

A more comprehensive and proactive role of patients in PV is becoming necessary, given the increasing number and complexity of the treatments approved. PAs could be key actors in the process of PV. The collaboration between PAs, Regulatory Authorities, Healthcare Providers and Pharmaceutical Companies can increase the "culture" of PV. Such partnership could induce a greater understanding of the drug's benefit/risk profile, a more frequent direct reporting of ADRs by the patients, and, for the doctors, the possibility of identifying those patients who are more likely to experience specific ADRs - (personalized safety). The doctor/patient's dialogue is of paramount importance: the patient needs to receive information regarding a drug's benefit/risk profile from the doctor and well understand the concept of risk benefit, at the basis of PV activities. An informed patient can better cope with his or her illness and the therapies, increasing the adherence to treatment, and finally, the success rate of treatment.

The PSC is actively contributing to developing a culture of PV between PAs and patients. Indeed, to fill the gap that emerged from this survey, the PSC has decided to set up projects, such as a training course on PV for patients and PAs, information material for patients, and provide valuable indications for decision-makers.

\section{ACKNOWLEDGEMENTS}

A special thanks to the Roche's team who worked on the realization of the PSC: Luisa de Stefano, Lisa Stagi, Lorella Colombi, Daniela Facchinello and Raffaella Robello.

\section{FUNDINGS}

The Patient Safety Council is an initiative supported by Roche S.p.A.

\section{CONFLICT OF INTEREST}

The authors declare that they have no conflict of interests. 


\section{REFERENCES}

1. Rimondini M, Busch IM, Mazzi MA, et al. Patient empowerment in risk management: a mixed-method study to explore mental health professionals' perspective. BMC Health Serv Res 2019;19(1):382.

2. WHO Guidelines Approved by the Guidelines Review Committee. WHO Guidelines on Hand Hygiene in Health Care: First Global Patient Safety Challenge Clean Care Is Safer Care. Geneva 2009.

3. Rose SL. Patient advocacy organizations: institutional conflicts of interest, trust, and trustworthiness. J Law Med Ethics 2013;41(3):680-7.

4. Guillamon NMA, Hernandez E, Gomez-Zuniga B. The Role of Patient Organizations in Participatory Medicine: Can Virtual Health Communities Help Participatory Medicine Accomplish Its Objectives? Journal of Participatory Medicine 2010;29:2:e21.

5. Daruwalla Z, Thakkar V, Aggarwal M, Kiasatdolatabadi A, Guergachi A, Keshavjee K. Patient Empowerment: The Role of Technology. Stud Health Technol Inform 2019;257:70-4.

6. Cavaller-Bellaubi M, Faulkner SD, Teixeira $B$, et al. Sustaining Meaningful Patient Engagement Across the Lifecycle of Medicines: A Roadmap for Action. Ther Innov Regul Sci 2021:1-18.

7. Manafò E, Petermann L, Vandall-Walker V, Mason-Lai P. Patient and public engagement in priority setting: A systematic rapid review of the literature. PLoS One 2018;13(3):e0193579.

8. Sheridan S, Schrandt S, Forsythe L, Hilliard TS, Paez KA. The PCORI Engagement Rubric: Promising Practices for Partnering in Research. Ann Fam Med 2017;15(2):165-70.

9. Bloom D, Beetsch J, Harker $M$, et al. The Rules of Engagement: CTTI Recommendations for Successful Collaborations Between Sponsors and Patient Groups
Around Clinical Trials. Ther Innov Regul Sci 2018;52(2):206-13.

10. Revised framework for interaction between the European Medicines Agency and patients and consumers and their organisations 2016. Available from https://www. ema.europa.eu/en/documents/other/revised-framework-interaction-between-european-medicines-agency-healthcare-professionals-their_en.pdf.

11. Parallel consultation with regulators and health technology assessment bodies: European Medicines Agency (EMA) and European Network for Health Technology Assessment (EUnetHTA) 2021. Available from https://www.ema.europa.eu/en/human-regulatory/research-development/ scientific-advice-protocol-assistance/parallel-consultation-regulators-health-technology-assessment-bodies.

12. Mechanisms of coordinated access to orphan medicinal products (MoCA) 2021. Available from https://www.eurordis.org/ content/moca.

13. Outcome report on pilot to involve patients in benefit/risk discussions at CHMP meetings 2017. Available from https://www. ema.europa.eu/en/documents/report/outcome-report-pilot-involve-patients-benef it/risk-discussions-chmp- meetings_en.pdf.

14. European Network for Health Technology Assessment (EUnetHTA). Patient input in Relative Effectiveness Assessments 2021. Available from: https://eunethta.eu/wp-content/uploads/2019/06/Final_290519Patient-Input-in-REAs.pdf.

15. Berglas S, Jutai L, MacKean G, Weeks L. Patients' perspectives can be integrated in health technology assessments: an exploratory analysis of CADTH Common Drug Review. Res Involv Engagem 2016;2:21.

16. Shaw D, Elger B. Putting patients on research ethics committees. J R Soc Med 2014;107(8):304-7.

17. Haerry D, Landgraf C, Warner K, et al. EUPATI and Patients in Medicines Research 
and Development: Guidance for Patient Involvement in Regulatory Processes. Front Med (Lausanne) 2018;5:230.

18. Paola K, Gasperini C. The value of direct patient reporting in pharmacovigilance. Ther Adv Drug Saf 2020;11:1-7.
19. Stagi L, Bocchi I, Bianco S, et al. Pharmacovigilance and the digital world in Italy: presentation of the results of a national survey. Ther Adv Drug Saf 2021;12:2042098620985991. 